\title{
ANALISIS KEKUATAN SAMBUNGAN LAS TABUNG GAS KAPASITAS 3 KG DENGAN MENGGUNAKAN METODE UJI TEKAN, UJI KOMPOSISI UNSUR KIMIA DAN UJI MIKRO
}

\author{
INDRA SURYA ${ }^{1}$, NARA PRABA ${ }^{2}$ \\ ${ }^{1}$ Mahasiswa Jurusan Teknik Mesin, Universitas Bandar Lampung \\ ${ }^{2}$ Dosen Pembimbing Program Studi Teknik Mesin, Universitas Bandar Lampung \\ J1. Zainal Abidin Pagar Alam No.26, Labuhan Ratu, Kedaton, 35142, Bandar Lampung Indonesia \\ Email : \\ indra.surya@ubl.ac.id \\ Narapraba025@gmail.com
}

\begin{abstract}
Abstrak
Pengujian dan pemeriksaan didalam industri logam, permesinan dan manufaktur dapat dibagi dalam dua kelas, yaitu pengujian dan pemeriksaan untuk keperluan pembuat dan pengujian serta pemeriksaan untuk keperluan pemakai. Pengujian dan pemeriksaan konstruksi las pada tabung gas memberikan penjelasan mengenai jaminan mutu produk dan konstruksi las yang dimana syarat utamanya merupakan kekuatan las. Pada pengujian kekuatan las dilakukan dua pengujian umum yaitu pengujian merusak dan pengujian tak merusak terhadap model dari konstruksi atau pada batang uji yang telah dilas sampai terjadi kerusakan pada model atau batang uji. Objek pengujian penelitian ini dilakukan pada sambungan las tabung gas kapasitas $3 \mathrm{~kg}$ yang merupakan konstruksi tabung gas konversi energi peralihan dari minyak tanah yang dipergunakan oleh masyarakat. Tabung gas kapasitas $3 \mathrm{~kg}$ merupakan bejana bertekanan yang menjadi tempat penyimpanan LPG (Liquid Petroleum Gas) dengan material pelat baja karbon sedang dengan tebal pelat 2,5 mm. Selain itu pula tabung gas kapasitas $3 \mathrm{~kg}$ memiliki 3 bagian umum yang terdiri dari gagang tabung, badan tabung, dan kaki tabung dengan tinggi tabung $\pm 80 \mathrm{~mm}$ dan diameter tabung $25 \mathrm{~mm}$. Pengujian dilakukan dengan cara pengujian bending/lengkung tekan, uji komposisi unsur kimia material sesuai dengan SNI 07-0410-1989. Hasil pengujian sambungan las tabung gas kapasitas $3 \mathrm{~kg}$ didapatkan kekuatan tekan rata-rata sebesar $1,74 \mathrm{~N} / \mathrm{mm}^{2}$. Pada pengujian bending dengan lengkung tekan hingga sudut $180^{\circ}$ tidak terjadi adanya pengaruh retakan las (no defeet). Sedangkan dalam pengujian unsur kimia material terdapat 31 unsur kimia didalamnya, dan dalam pengujian mikro hanya ada unsur ferrite dan perlite saja.
\end{abstract}

Kata kunci : Tabung gas LPG 3kg; Uji mikro; Uji tekan; Uji komposisi unsur kimia. 


\section{PENDAHULUAN}

\section{Latar Belakang}

LPG (liquid petroleum gas) pada saat ini merupakan bahan bakar yang sering digunakan oleh rumah tangga ataupun industri. Di zaman yang modern seperti sekarang masyarakat lebih memilih menggunakan gas LPG sebagai bahan bakar untuk kompor gas. Selain mudah, hemat, efisien, gas LPG juga aman asalkan sesuai prosedur penggunaannya. Di Indonesia sendiri gas LPG masih di subsidi oleh pemerintah untuk gas LPG $3 \mathrm{~kg}$. Pertamina selaku badan usaha milik negara bekerjasama dengan SPPBE untuk mendistribusikan gas LPG.

Untuk membatasi subsidi tersebut, pemerintah mengeluarkan peraturan presiden republik Indonesia nomor 104 tahun 2007 tentang penyediaan, pendistribusian, dan penetapan harga LPG. Tetapi LPG $3 \mathrm{~kg}$ hanya untuk masyarakat miskin, oleh sebab itu pendistriannya harus tepat sasaran. Untuk itu juga tersedia LPG yang non subsidi untuk masyarakat yang mampu. LPG yang non subsidi juga tersedia dalam beberapa varian diantaranya yaitu LPG tabung $50 \mathrm{~kg}$, LPG tabung $12 \mathrm{~kg}$, dan $5 \mathrm{~kg}$, atau lebih dikenal dengan bright gas. Untuk mengatur distribusi gas, pemerintah bekerjasama dengan swasta dengan memanfaatkan bekas agen dan pangkalan minyak tanah menjadi agen dan pangkalan gas LPG. Tabung gas kapasitas $3 \mathrm{~kg}$ merupakan bejana bertekanan yang menjadi tempat penyimpanan LPG dengan material pelat baja karbon sedang dengan tebal pelat 2,5 $\mathrm{mm}$. Selain itu pula tabung gas kapasitas $3 \mathrm{~kg}$ memiliki 3 bagian umum yang terdiri dari gagang tabung, badan tabung, dan kaki tabung dengan tinggi tabung $\pm 80 \mathrm{~mm}$ dan diameter tabung $25 \mathrm{~mm}$.

\section{Tujuan Penulisan}

Tujuan penelitian yang akan dilakukan pada sambungan las tabung gas kapasitas $3 \mathrm{~kg}$ yaitu:

1. Melakukan uji komposisi unsur material.

2. Melakukan uji tekan.

3. Melakukan pengujian mikro. 


\section{TINJAUAN PUSTAKA}

\section{Kontruksi Tabung}

Pada kontruksi tabung gas kapasitas $3 \mathrm{~kg}$ terdiri dari beberapa bagian tabung yaitu:

- Badan tabung, tediri dari bagian atas dan bawah (top dan bottom).

- Cincin leher (neck ring).

- Pegangan tangan (hand guard).

- Cincin kaki (foot ring).

\section{Proses PembuatanTabung Gas}

Pada proses pembuatan tabung terdapat beberapa langkah yaitu sebagai berikut:

1. Bahan pelat baja karbon dipotong sesuai dengan ukuran dan diberikan pelumas sebelum masuk pada proses pembentukan.

2. Pembentukan dilakukan dengan cara di press (Deep Drawing) dan hasilnya merupakan komponen dari badan tabung pada bagian atas dan bawah (top and bottom).

3. Komponen tabung bagian atas kemudian dilubangi untuk pemasangan cincin leher.

4. Pemasangan cincin leher dilakukan dengan cara pengelasan menggunakan las busur logam gas (gas metal arcwelding).

5. Sambungan las antara bagian atas dan bawah tabung terhadap badan silinder menggunakan pengelasan berbentuk lastumpang.

6. Penyambungan pegangan tangan dan cincin kaki dengan badan tabung, dilakukan dengan cara pengelasan busur listrik (shielded metal arc welding) dengan bentuk las sudut (fillet)

7. Pengelasan dilakukan oleh juru las atau operator las yang memenuhi standar kompetensi jurulas.

8. Setiap tabung harus mendapatkan perlakuan panas untuk pembebasan tegangan sisa (annealing), yaitu pada suhu $630^{\circ} \mathrm{C} \pm 25^{\circ}$ sekurang-kurangnya 20 menit.

9. Untuk mencegah timbulnya karat pada permukaan luar tabung harus dilakukannya perlindungan dengan pelapisan cat. Sebelum dilakukan pengecatan harus didahului proses pembersihan dengan cara shot blasting diseluruh permukaan tabung. Pengecatan pertama menggunakan cat dasar (primer coat) dengan tebal 25 mikron sampai 30 mikron selanjutnya menggunakan cat akhir (top coat) dengan tebal 25 mikron sampai 30mikron.

\section{Bahan Baku Tabung LPG}

Dalam tahap pembuatan tabung LPG, penggunaan bahan baku dibagi menjadi 3 bagian yakni, antara lain:

1. Badan tabung 
Bahan untuk bagian badan tabung sesuai dengan SNI 07-3018-2006, baja lembaran pelat dan gulungan canai panas untuk tabung gas (Bj TG) atau JIS G 3116, kelas SG 26 (SG 225), SG30 (SG295).

2. Cincin leher (neck ring)

Bahan untuk bagian cincin leher sesuai dengan JIS G 4051 kelas S17C sampai dengan S45C.

3. Cincin kaki (foot ring) dan pegangan tangan (hand guard)

Bahan untuk bagian cincin kaki dan pegangan tangan sesuai dengan SNI 07-0722-1989, baja canai panas untuk kontruksinumum, JIS G 3101 kelas SS400 atau sesuai bahan untuk badan tabung yang bersangkutan.

\section{Teori Uji Komposisi Material}

Tujuan utama dari pengujian komposisi bahan dalam penelitian ini yaitu untuk mendapatkan komposisi bahan yang terkandung dalam plat baja tabung gas LPG $3 \mathrm{~kg}$. Proses dari pengujian komposisi bahan material yaitu untuk mendapatkan hasil seberapa besar nilai unsur penyusunan bahan.

5. Teori Uji Bending/LengkungTekan

Untuk mengetahui kekuatan bending suatu material dapat dilakukan dengan pengujian bending terhadap material tersebut.Kekuatan bending atau kekuatan lengkung adalah tegangan bending terbesar yang dapat diterima akibat pembebanan luar tanpa mengalami deformasi yang besar atau kegagalan.

\section{Teori Uji Mikro}

Pengujian mikro adalah suatu pengujian mengenai struktur bahan melalui pembesaran dengan menggunakan mikroskop khusus metalografi. Dengan pengujian mikro struktur, kita dapat mengamati bentuk dan ukuran kristal logam, kerusakan logam akibat proses deformasi, proses perlakuan panas dan perbedaan komposisi.

$\longrightarrow(4)$




\section{METODOLOGI PENELITIAN}

\section{Waktu dan tempat penelitian}

Penelitian ini dilakukan di beberapa tempat, yaitu:

1. Pemotongan tabung gas dilakukan di Laboratorium Universitas Bandar Lampung (UBL).

2. Pembentukan specimen dilakukan di Laboratorium Universitas Bandar Lampung (UBL).

3. Pengujian tekan, struktur mikro, dan komposisi material dilakukan di Lembaga Ilmu Pengetahuan Indonesia (LIPI).

\section{2. langkah pengujian tekan}

Langkah-langkah pengujian bending pada penelitian ini adalah sebagai berikut:

1. Siapkan spesimen..

2. Hidupkan mesin uji bending yang digunakan.

3. Masukan data specimen dan menetapkan kecepatan penekanan pengujian bending.

4. Pasang specimen pada mesin, pastikan terpasang dengan benar.

5. Atur jarak indentor terhadap specimen dengan tepat.

6. Jalankan mesin uji Bending.

7. Setelah specimen mengalami crack/retak hentikan proses penekan padas pesimen.

8. Simpan data hasil pengujian pada komputer.

9. Ulangi langkah1-3 hingga semua specimen selesai di uji bending.

10.Setalah semua specimen selesai diuji, print out semua data hasil pengujian. 
Diagram Alir

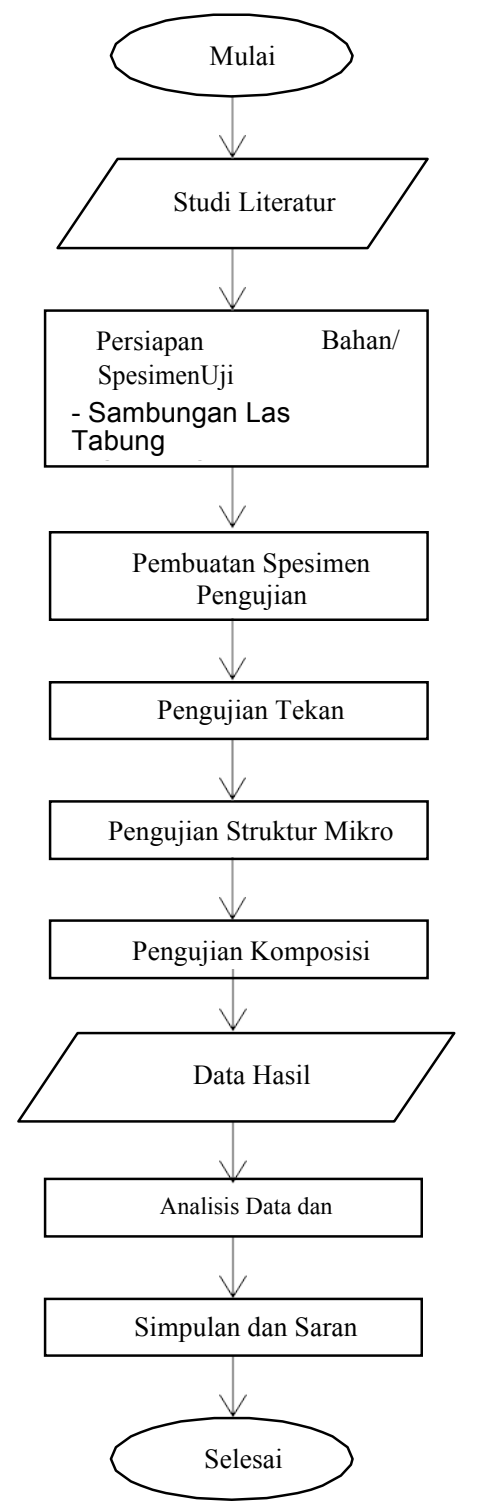

Gambar 3.10 Diagram alir 


\section{HASIL DAN PEMBAHASAN}

\section{Hasil Penelitian}

\section{Uji tekan}

Uji tekan adalah suatu alat uji mekanik yang berguna untuk mengukur dan mengetahui kekuatan benda terhadap gaya tekan. Uji tekan ini memiliki kinerja yang bagus dan berkualitas untuk mengetahui kekuatan pada suatu benda.

Pada pengujian tekan penelitian ini menggunakan alat Universal Testing Machine, dibawah ini adalah tabel hasil pengujian tekan pada sambungan tabung gas LPG kapasitas $3 \mathrm{~kg}$.

dibawah ini adalah tabel hasil kekuatan tekan pada pengujian tekan dengan bahan sambungan las tabung gas LPG kapasitas $3 \mathrm{~kg}$.

Tabel 4.3 Hasil Uji Tekan

\begin{tabular}{|c|c|c|}
\hline NO & Kode Sampel & $\begin{array}{c}\text { Kuat Tekan } \\
\left(\mathrm{N} / \mathrm{mm}^{2}\right)\end{array}$ \\
\hline 1 & A I/ M & 1,92 \\
\hline 2 & A II & 1,63 \\
\hline 3 & A III & 1,67 \\
\hline Rata-rata & & 1,74 \\
\hline
\end{tabular}

1. Dari hasil uji tekan kode sampel A I/ M dengan panjang bahan $10 \mathrm{~cm}$ dan lebar $1,3 \mathrm{~cm}$ didapatkan hasil kekuatan tekan sebesar $1,92 \mathrm{~N} / \mathrm{mm}^{2}$.

2. Dari hasil uji tekan kode sampel A II dengan panjang bahan $9,5 \mathrm{~cm}$ dan lebar $1,3 \mathrm{~cm}$ didapatkan hasil kekuatan tekan sebesar $1,63 \mathrm{~N} / \mathrm{mm}^{2}$.

3. Dari hasil uji tekan kode sampel A III dengan panjang bahan 9,3 cm dan lebar 1,2 cm didapatkan hasil kekuatan tekan sebesar $1,67 \mathrm{~N} / \mathrm{mm}^{2}$.

4. Dari ketiga pengujian sampel diatas maka didapatkan hasil kuat tekan rata-rata sebesar $1,74 \mathrm{~N} / \mathrm{mm}^{2}$.

5. Jadi semakin panjang dan semakin kecil bahan maka akan didapatkan hasil kekuatan tekan yang lebih maksimal. 


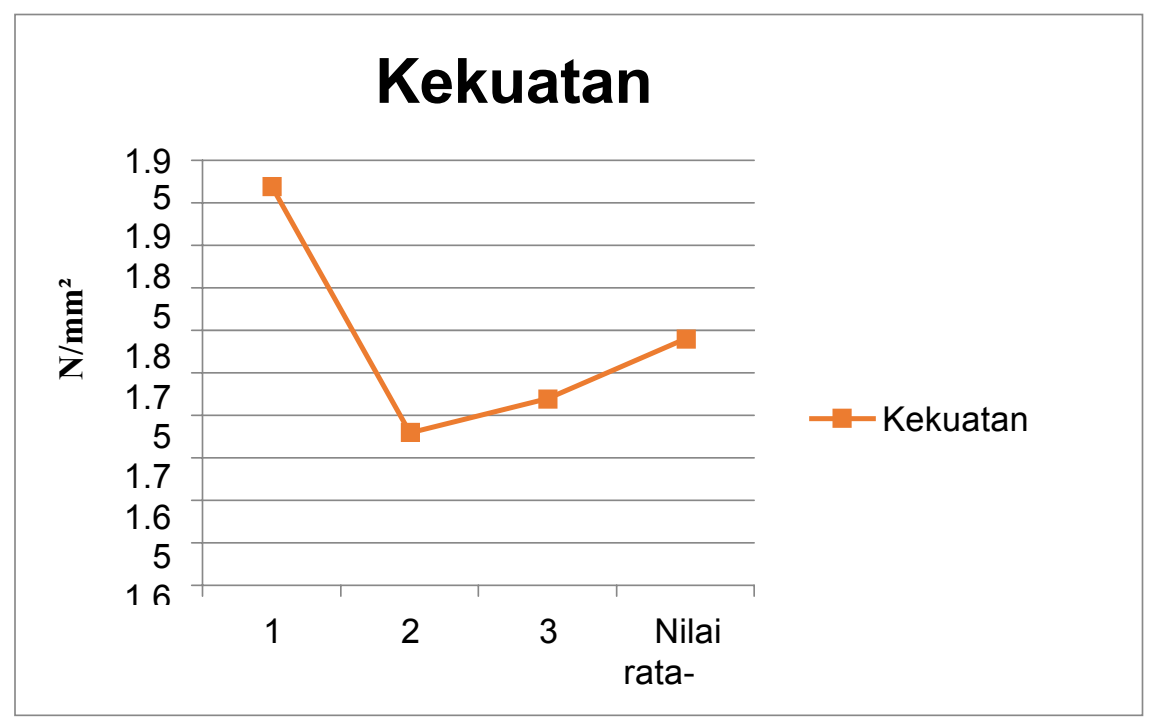

Gambar 4.1 Grafik Hasil Uji Tekan

Grafik uji tekan menunjukan hasil nilai pengujian memiliki dampak terhadap kekuatan material yang di tekan tersebut berdampak pada kekuatan tekannya.

\section{Hasil Pengujian Komposisi Unsur Kimia Material}

Untuk mengetahui persentase unsur kimia yang terkandung didalam spesimen tabung gas LPG $3 \mathrm{~kg}$, unsurunsur yang terkandung didalam baja sangat mempengaruhi sifat mekanis dari baja yang bersangkutan. Jenisjenis baja pada umumnya ditentukan berdasarkan kandungan unsur karbon yang terkandung didalam material tersebut.

\section{Hasil Uji Mikro}

Pengujian mikro adalah suatu pengujian mengenai struktur bahan melalui pembesaran dengan menggunakan mikroskop khusus metalografi. Alat yang digunakan pada pengujian mikro adalah alat mikroskop Nikon eclipse.

Pengujian mikro untuk bahan sambungan las tabung gas LPG $3 \mathrm{~kg}$ ini dilakukan dengan mikroskop pembesaran antara 100x sampai 500x untuk memperlihatkan ukuran butir dan bentuk, struktur butir (ferit, perlit dan sebagainya), dan kerusakan mikro seperti retak dan keporiannya.

1. FERRITE $(\alpha)$ adalah Larutan padat Interstisi dari atom-atom karbon pada besi murni.

FERRITE mempunyai sifat lunak dan ulet

2. SEMENTITE ( $\mathrm{Fe} 3 \mathrm{C}$ ) adalah senyawa logam yang mempunyai kekerasan tinggi terkeras diantara fasa-fasa yang mungkin terjadi pada baja tetapi rapuh.

$(8)$


3. PERLITE $(\alpha+\mathrm{Fe} 3 \mathrm{C})$ adalah campuran khusus dari dua fasa yaitu ferrite dengan sementite yang terbentuk secara bersamaan hanya terjadi pada temperature dibawah 723 celcius. Perlite mempunyai sifat yang kuat dan cukup keras.

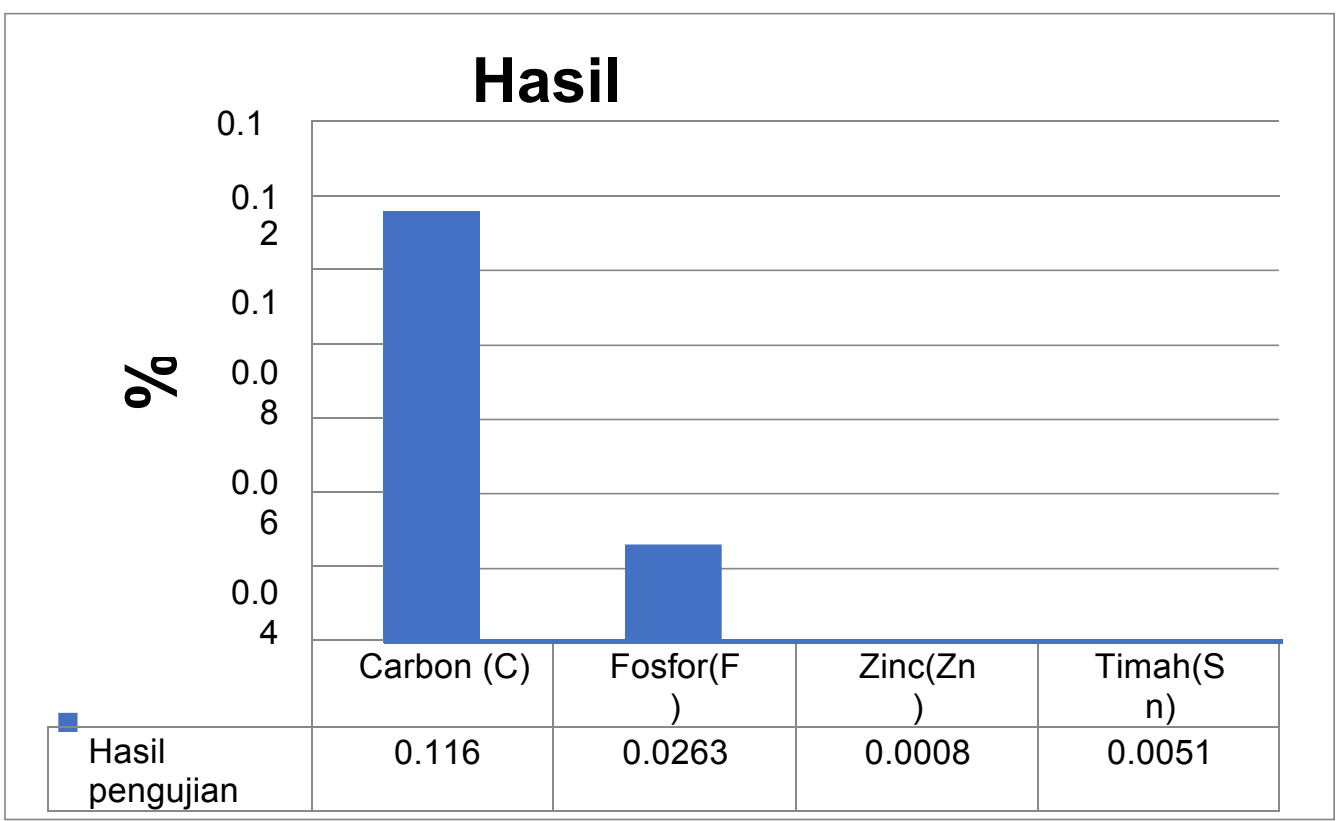

Gambar 4.9 Diagram balok Hasil Analisa Pengujian Komposisi

Pada hasil perbandingan pengujian komposisi unsur kimia pada tabung gas LPG $3 \mathrm{~kg}$ pada tabel 4.3 diatas menunjukan bahwa komposisi unsur kimia yang paling banyak di bahan baja tabung gas LPG $3 \mathrm{~kg}$ adalah komposisi Carbon(C) senilai 0,1160.

Pembahasan mengenai hasil pengujian unsur kimia, dengan diagram fasa, menunjukkan jika terkandung unsur Carbon (C) sebesar 0,1160 yang membuktikan bahwa hanya terkandung unsur ferrite dan perlite saja didalam pengujian mikro. Dengan nilai sebesar 0,1160 maka dapat dikatakan sebagai baja carbon rendah. 


\section{KESIMPULAN DAN SARAN}

\section{$5.1 \quad$ Kesimpulan}

Setelah melakukan analisis dan perhitungan terhadap data hasil pengujian mengenai sambungan las pada tabung gas kapasitas $3 \mathrm{~kg}$ dapat disimpulkan diantaranya :

1. Pada hasil pengelasan setiap tabung yang diproduksi menunjukan kekuatan tekan rata-rata pada setiap sambungan las sebesar $1,74 \mathrm{~N} / \mathrm{mm}^{2}$.

2. Pada uji komposisi material tabung gas $3 \mathrm{~kg}$ terdapat 31 unsur kimia didalamnya dan yang paling tinggi adalah kandungan unsur Fe sebesar 97,4000.

3. Hasil pengelasan badan tabung yang diproduksi seluruhnya diatas rata-rata yang dianjurkan SNI ini merupakan tingkat keamanan bagi masyarakat yang selalu mengkhawatirkan terjadinya ledakan tabung gas kapasitas $3 \mathrm{~kg}$, apa yang terjadi dilapangan ledakan tabung gas banyak ditimbulkan dari regulator yang bocor, bukan dari tabung gasnya.

4. Pada hasil foto mikro menunjukkan adanya perbedaan pada permukaan dan cross section dari material tabung gas tersebut, yaitu pada tebal bahan dan kasarnya bahan, tetapi hanya ada 2 unsur yaitu ferrite dan perlite saja.

\subsection{Saran}

Setelah melakukan penelitian dan menyimpulkan hasil penelitian maka disarankan:

1. Pada penggunaan tabung gas bisa memperhatikan rawannya sambungan las terhadap benturan pada saat pendistribusiannya yang bisa menimbulkan cacat pada area sambunga las.

2. Pengujian ini bisa jadi acuan sebagai tingkat perbandingan mengenai keamanan dan keselamatan bagi masyarakat.

3. Pengujian yang belum menggunakan alat berteknologi baik bisa dilakukan kedepannya agar mendapatkan hasil yang lebih memuaskan.

4. Pada pengujian selanjutnya sebaiknya untuk lebih memperhatikan tujuan yang lebih baik lagi, seperti menambahnya beberapa pengujian lainnya untuk tabung gas LPG $3 \mathrm{~kg}$ agar mendapatkan hasil yang lebih efisien. 


\section{DAFTAR PUSTAKA}

MS. Surdia, Tata. Shinroku, Saito. 1999. Pengetahuan Bahan Teknik, Jakarta: PT. Pradnya paramita JalanBunga 8-8a

Harsono, W. Dan Toshie, O., 2010, Teknologi Pengelasan Logam, Edisi ke-4 Pradnya Paramita, Ltd.

Hayden, H.W, Moffat, W.G, dan Wulff, J., 1965, “ The Structure and Properties Material”, Edisi ke-3, Mechanical Behavior, New York.

Surdia, T, dan Saito S., 1992, "Pengetahuan Bahan Teknik", Edisi ke-3, Pradnaya Paramita, Jakarta.

ASME Section VIII, Division 2, Pressure Vessel Code "API Exploration \& Production Standards Conference On Oilfield Equipment and Materials". Ohio USA PA : The Equity Engineering Group, Inc.

SNI 19-1452-2006 Mengenai Tabung Baja LPG SNI 07-0408-1989 Cara Uji

Tarik Logam

SNI 07-0410-1989 Cara Uji Lengkung Tekan Logam SNI 05-3563-1994 Bejana Tekan

$1-\mathrm{A}$

SNI 07-3018-2006 Baja Lembaran Pelat dan Gulungan Canai Panas Untuk Tabung Gas (Bj TG)

SNI 07-0722-1989 Baja Canai Panas untuk Konstruksi Umum http://sisni.bsn.go.id/

Februari 2011

http://besibaja.ptgis.com/index.asp?cp=detail_sni\&id=8

Maret 2011

www.scribd.com/doc/47699562/LP-011-IDN

Januari 2011 